\title{
Assessing Customer Satisfaction with Non-Profit Organizations: Evidence from Higher Education
}

\author{
Lily Huang \\ City University of Hong Kong \\ Zhilin Yang \\ Victoria University of Wellington
}

Gerald Hampton

New Mexico State University

\begin{abstract}
This study empirically examines several key issues concerned with assessing customer satisfaction in the context of higher education. Data were obtained from 1475 students, with various characteristics, who were enrolled at four large universities. The results indicate that dissatisfied and satisfied students are significantly different when assessed in terms of five education service attributes. The performance model is found to be capable of explaining customer satisfaction more powerfully than either the disconfirmation or the multi-attribute model. In addition, some student characteristics are considered to be crucially important in their effects on expectation and performance of education service attributes, which, in turn, exert influence on assessment of customer satisfaction.
\end{abstract}

Keywords: Customer Satisfaction, Student Satisfaction, Performance Model, High Education

\section{Introduction}

For the past three decades, increasing numbers of universities have perceived that students are important customers, and have utilized marketing thinking and practice to attract, satisfy, and retain students (Conant, Brown, and Mokwa, 1984; Ferguson, Wisner, and Discenza, 1986; Hampton, 1993; Douglas, McClelland, and John Davies, 2008; Gruber,et al, 2010). Many administrators at post-secondary schools have realized that customer satisfaction is an indispensable means of creating a sustainable advantage in the competitive environment of higher education (Douglas, McClelland, and John Davies, 2008). The study of satisfaction, especially in the service industry, as Patterson et al (1996) have observed, is an important, yet underdeveloped area. The need to measure customer satisfaction is a corollary to effectively implementing the marketing concept. In the specific context of higher education, there have been some recent studies which have strived to assess satisfaction from customer perspectives (e.g. Hampton 1993; Douglas, McClelland, and John Davies, 2008; Gruber,et al, 2010). Due to 
the complicated nature of higher education service, assessing student satisfaction with higher education still remains a huge challenge. The two essential issues are: (1) what attributes of student satisfaction should be assessed; and (2) how it can be assessed.

In this paper an attempt has been made to examine several issues involved in effectively assessing student satisfaction with higher education, employing cross-university surveys. For this purpose, the study will first examine the attributes of education service and the differences of education service attributes between satisfied and dissatisfied students. Then, it will evaluate whether most often used models or approaches can explain student satisfaction with higher education, and which one is the most powerful tool. Finally, it will examine whether student characteristics have significant effects on the performance of education service attributes, given that they are moderator variables.

This study has made several contributions to customer satisfaction knowledge: (1) it offers cross-sectional study of student satisfaction with higher education.; (2) it aims to identify service attributes based on marketing mix; (3) it examines some models of satisfactions including multi-attribute attitude theory, disconfirmation theory and gap analysis in the context of the higher education area; (4) it incorporates student variables as moderators through examination of effects on student expectations and perceived performance of service attributes.

\section{Theory and Hypotheses Development}

\section{Multi-Attribute Services and Satisfaction}

Satisfaction is defined as an effective state that is the emotional reaction to a service experience (Olive, 1980, Cadotte, Woodruff, and Jenkins 1987, Yang and Fang 2004). Service is inherently variable and lacks consistency because of its intangibility and the complicated needs and desires of customers. To overcome this weakness, multi-attribute attitude models, which are used to correctly identify the underlying dimensions with which a customer evaluates perceived service performance and expectations, was suggested in the context of customer satisfaction (Yang and Peterson 2004). This model has some advantages in the service area, both theoretical and managerial. First, customers are more likely to render evaluations of their service experiences of satisfaction at an attribute level, rather than at the product level (Gardial et al. 1994). Second, an attribute-based approach enables researchers to conceptualize commonly observed phenomena, such as customers experiencing mixed feelings toward a package of services. The attributelevel approach provides a simple and elegant solution: Mixed feelings toward a product exist because a customer may be satisfied with one attribute, but dissatisfied with another. Third, an attribute-level approach to satisfaction affords researchers a higher level of specificity and diagnostic usefulness compared with the product level or "overall" approach (Yang, Peterson, and Huang, 2001; Yang, Peterson, and Cai, 2003). Finally, there is some evidence that attribute-level performance/disconfirmation and overall satisfaction are qualitatively different constructs (Oliva, Oliver, and Bearden 1995), and, if treated interchangeably, specific product issues may be hidden by global customer satisfaction responses (Oliva, Oliver, and Bearden 1995; Yang, Peterson, and Cai, 2003). Thus, studying satisfaction at the attribute level can help extend both conceptual and empirical understanding of the phenomenon. As to the context of higher education service, it is logical to regard service attributes as good bases of satisfaction evaluation. 
Instead of searching for more appropriate service attributes, some studies in satisfaction research have tried to examine the effect of more moderate variables, such as information satisfaction, desire (Spreng, MacKenzie and Olshavsky, 1996), price satisfaction (Voss, Parasuraman, and Dhruv Grewal 1998), fairness (Patterson, Johnson, and Spreng, 1997). These variables are mostly related to some marketing mix variables. For example, information satisfaction is related to promotion, and attributes satisfaction is related to product.

Following their reasoning, we can even explore more contingent variables, such as package or place. Key reasons for searching for a wider range of moderators may reside in efforts to build a more universal model for satisfaction. However, we think that these moderate variables are often incorporated into service or product attributes by the customer and may be more appropriately listed as attributes other than moderate variables. Some scholars point out that different satisfaction processes operate under different conditions, such as across different product categories, for high versus low-involvement products, or for products versus services, often yield conflict results (Anderson 1994; Bolton and Drew 1991b; Cadotte et al. 1987; Halstead et al. 1994; Oliver 1989; Spreng et al. 1996). Therefore, we would propose that, from a marketing perspective, service attributes should be based on marketing mix while recognizing the specific service characteristics.

In their study of reviewing the impact of service attributes on customer satisfaction and dissatisfaction, Iacobucci and Ostrom (1995) identified some marketing related aspects of service, notably price, level of quality, friendliness of the service personnel, the degree of customization of the service, all of which are efficient factors in explaining customer satisfaction. In the higher education context, there are many versions used to measure higher education service attributes; most are essentially related to marketing mix variables. For instance, a widely used and well-known one (e.g. DeVore and Handal, 1981; Hampton, 1993), which was created by Betz, Klingensmith and Menne (1970), includes five factors, namely, studying conditions, recognition, compensation, quality of education, and social life. These factors are essentially related to marketing mix variables: compensation is related to price, quality of education to product, social life to package, recognition and studying condition is related to place. Therefore, based on marketing mix variables, we construct education service attributes though revising the design of Betz, Klingensmith and Menne (1970).

Previous studies illustrate that different service attributes of higher education embody varying degrees when influencing student satisfaction. Basically, quality of education is the most important factor and is related directly to student satisfaction (Howard and Maxwell, 1980, Hampton, 1993). Other resources are somewhat confused, depending on the methods employed, the nature of colleges and the samples that researchers collected.

Once the primary attributes of education service are determined, the next relevant issues are: which group should we be carefully looking for? Satisfied students or dissatisfied students, or both? Most researches done to date in durable goods areas put emphasis on dissatisfied customers. However, quite a few studies in the service industry and the higher education area show that the causes of dissatisfaction are not necessarily linked to the observer of the (dis) satisfaction (e.g. Johnson, 1995, Yang and Fang 2004). Johnson (1995) suggests that it is more appropriate to study the causes of satisfaction instead of dissatisfaction for satisfaction in the 
service industry. From a managerial standpoint, it is important for administrators to understand the different attributes between satisfied students and dissatisfied students (Yang and Fang, 2004). Therefore, we propose the following Hypotheses:

$\mathrm{H}_{1 \mathrm{a}}$ : All five marketing mix related higher education attributes are significantly related to customer satisfaction with higher education.

$\mathrm{H}_{1 \mathrm{~b}}$ : For these five service attributes, satisfied students will significantly differ from dissatisfied students.

\section{Which Model Predicts Best?}

Due to the complicated nature of higher education as a service industry, assessing student satisfaction with higher education still remains a frequently troublesome issue. Quite a few models have been employed to examine the causes of student satisfaction with college from customer perspectives (e.g. Barry, Gilly and Schucancy, 1982; Hampton 1983, 1993; Hawes and Gilsan 1983; Schmidt, Debevec, and Comm, 1996; Douglas, McClelland, and John Davies, 2008; Gruber,et al, 2010). Among these studies, the following three models or methods were heavily employed to measure student satisfaction with higher education: disconfirmation model (Conant, Brown, and Mokwa, 1984) or gap analysis (Hampton, 1993); multi-attributes approach (Douglas, McClelland, and John Davies, 2008; Gruber, et al, 2010).

\section{Disconfirmation Model.}

The dominant conceptual model in the satisfaction literature is the model of disconfirmation of expectation. This model theorized that satisfaction is a function of the discrepancy between a customer's expectation about the performance of a product and obtained product performance (Oliver, 1978, Churchill \& Surprenant, 1982; Tse \& Wiltob, 1988; Yi, 1990, 1994). The expectation or disconfirmation model is also the most popular model for satisfaction studies in the higher education context (e.g. Conant, Johnson, and Mokwa, 1984; Hampton, 1993). Hampton (1993) used gap analysis to detect the factors and items that are mostly concerned with student satisfaction.

Some customer satisfaction researchers have questioned the expectation model. La Tour and Peat have been highly critical of this approach taken by satisfaction research (1978). First, they suggest that this major methodological problem centers around researches measuring the impact of expectation on perceived product performance, rather than measuring the impact of expectation on satisfaction. This occurs because performance evaluations do not contain an evaluation component; and therefore, there is no way to ascertain whether the customer is satisfied or dissatisfied with the level of obtained performance. Furthermore, satisfaction is a relative phenomenon rather than an absolute one. Though the disconfirmation of expectation also assumes customer satisfaction is a relative one, it is too strict to account fully for customer satisfaction.

\section{Multi-attributes weighted attributes model.}

Multi-attribute attitude models have received considerable attention from marketing researchers and practitioners (Shocker and Srinivasan, 1979, Yang, Peterson, and Cai, 2003). The basic notion of these different models is that customers form attitudes toward products or services on the basis of their attributes, which in turn, are used to explain and/or predict product/brand, 
service preference or choice. The multi-attributes model has actionable managerial implications because, as a diagnostic approach, it is useful in detecting factors that could improve overall satisfaction of the product or service.

\section{Performance Model.}

With regard to services, based on Oliver (1980), Jayanti and Jackson (1991) state that "when performance judgments tend to be subjective (as in services due to intangibility) expectations may play only a minor role in the formation of satisfaction" (p. 603). They suggest that satisfaction in services may be a function of performance alone. Performance alone could be enough to explain customer satisfaction.

Among the relative importance of the effects of performance, weighted attributes and disconfirmation on customer satisfaction, the empirical results are often conflicted. Churchill and Surprenant (1982) found that both disconfirmation and performance were significant antecedents of satisfaction for a low-involvement product, but only performance was significant for a high-involvement product. In other instances, Tse and Wilton (1988) found that both disconfimation and performance had significant effects for a high-involvement product, but performance was stronger. Patterson (1993) also found the opposite pattern with a high-involvement product (home heater), in that performance had a stronger effect than disconfirmation. This has prompted some scholars to suggest that different satisfaction processes operate under different conditions, such as across different product categories, for high versus low-involvement products, or for products versus services (Anderson 1994; Bolton and Drew 1991b; Cadotte et al. 1987; Halstead et al. 1994; Oliver 1989; Spreng et al. 1996).

In the higher education context, most studies utilized the disconfirmation model and found that disconfirmation has significant impact on satisfaction (Hampton, 1993). There is a lack of consistent results, however, with some studies showing a stronger effect of performance, whereas others show a stronger effect of disconfirmation. Furthermore, it is surprising that there is a lack of studies comparing the relative effects of all three concept paradigms on student satisfaction.

Based on recent studies in the service area, Hypotheses 2 and 3 are proposed as the following:

$\mathrm{H}_{2}$ : Performances, Multi-attributes, Disconfirmations (Gaps) will have significant impact on student satisfaction.

$\mathrm{H}_{3}$ : $\quad$ Performance directly accounts for student satisfaction with higher education and is the best predictor in the higher education context.

\section{Student Characteristics as Moderators}

Empirically, customer satisfaction/dissatisfaction is found to be correlated with various socioeconomic and demographic variables, although the statistically significant relationship accounts for relatively small percentages of variance in customer satisfaction/dissatisfaction (Day and Bodur, 1977; Ash 1978). In their model of determinants of customer satisfaction with business-to-business professional service, Patterson, Johnson and Spreng (1996) found that the service attributes are all important to customer satisfaction/dissatisfaction, and that their importance varies with such moderators as purchase situation and individual level. Within 
the context of higher education, Astin (1987) argued that student satisfaction with college is determined not only by service attributes, but by the impact of student characteristics. Some prior studies have examined the relationships between student variables, such as gender, major, age, ethnicity, GPA (Howes, Maxwell, 1980), part or full time status, and education service attributes (cf. Starr, Bertz, and Menne, 1972; Powers 1985; Darren et al, 1989; Stage 1988). Sturtz (1971) found that older students pay more attention to their recognition and education quality than younger students. In addition, older students are likely to require less social life or informal activities on campus since the family unit plays a larger part in older students' lives (Hiltumen, 1965). According to Bean and Vesper (1981), recognition is more important for female students than male students.

Furthermore, some studies address the indirect effects of some student variables on student satisfaction with higher education. For example, Terkla and Pagano (1990) pointed out that financial situation affects student expectation for university education quality and influences their satisfaction with higher education. While examining the effects of major on satisfaction with college, Schmidt, Debevec and Comm (1987) find that different majors lead to various perceptions of service attributes, which, in turn, influence their perception of satisfaction with college.

However, no comprehensive investigations have been done on how student characteristics indirectly affect satisfaction with higher education via performance or expectation of service attributes. To investigate whether the importance or expectation of education service attributes (recognition, education quality, social life, compensation and studying condition) varies across contingency variables, studies should incorporate student characteristics into design as moderator variables. Since relatively few studies on these student variables impacting service attributes have been conducted previously in customer satisfaction literature in the higher education context, propositions of the relationship between these variables represented and satisfaction with higher education may be a step toward an integrated theory of student satisfaction with higher education. As a result, Hypotheses $3 \mathrm{a}$ and $3 \mathrm{~b}$ are as follow:

$\mathrm{H}_{3 \mathrm{a}}$ : The effects of performance of education service on student satisfaction will vary on the basis of student characteristics.

$\mathrm{H}_{3 \mathrm{~b}}$ : The effects of expectation of education service on student satisfaction will vary on the basis of student characteristics.

\section{Methodology}

\section{Measures}

A questionnaire developed by Betz, Klingensmith and Menne (1971) was used as a guide to develop the survey for this study. Their findings showed that College Student Satisfaction Questionnaire (CCSQ) is one of the few psychometrically sound instruments for the measurement of student satisfaction within the context of higher education. In its present from, CSSQ consists of five scales, namely, studying conditions, recognition, compensation, quality of education, and social life. Their survey contained seventy statements relating to student education services and encounters. 
Through a pretest procedure, this instrument was refined and condensed. Several classes of students, both graduate and undergraduate, were asked to determine which of these seventy statements were relevant to their educational experience. They were also asked to add attributes that were missing from the list. The final version contained nine items for each attribute of education service. Each item asked for two responses: performance and importance. Performance was measured by having students respond to the items on a seven-point Likert scale that ranged from very satisfied to very dissatisfied. Importances were measured on a similar scale ranging from very important to very unimportant. Student expectation has been measured by the importance of all service attributes (Hampton, 1993; Polcyb, 1986).

The database contained measures for several constructs. There was one dependent measure for this analysis: overall satisfaction. A seven-point overall measure of how students felt about the performance of education service was utilized on a range from, "Overall I'm very satisfied"' to "Overall I am very dissatisfied." Furthermore, to evaluate the contingent effect of student characteristics on satisfaction, eleven student variables were listed as general information at the end of questionnaire: (1) major, (2) gender, (3) age, (4) class, (5) year in the school, (6) employment status, (7) financial aid, (8) GPA, (9) ethnicity, (10) religion (11) part versus full time job. Each variable was measured by number in terms of the order showed in questionnaire.

\section{Sample}

Participants in this survey were students who were randomly selected from three major Universities in the USA, one business college in The Netherlands, and alumni from one of three universities. Using alumni as participants is also suggested by Gwinner and Beltramini, 1995. Students were from different majors, and classes. This procedure was used in order to obtain a sample reasonably representative of students across different universities. Except for alumni to whom questionnaires were mailed, all the questionnaires were finished in class. Students were instructed before answering the questionnaire. The collected effective sample was 1475 .

\section{Model Construction}

Performance model. In this model, satisfaction is a function of performance of all attributes. We call this model the "performance model", which can be simply expressed as :

$$
\mathrm{S}_{\text {edu }}=\sum_{\mathrm{I}=1}^{\mathrm{n}} \mathrm{P}_{\mathrm{i}}
$$

where : $\mathrm{S}_{\text {edu }}=$ satisfaction with education serice; $\mathrm{P}_{\mathrm{i}}=$ performance of attribute $\mathrm{I}$; $\mathrm{n}=$ number of attributes.

Disconfirmation Model (gaps model). The disconfirmation model in this study can be computed by the following formula, despite its complicated nature in some studies.

$$
\mathrm{n}
$$

$$
\left.\mathbf{D i}=\sum_{\mathrm{I}=1} \mathrm{P}_{\mathrm{i}}-\mathrm{I}_{\mathrm{i}}\right)
$$

Where: $\mathrm{D}_{\mathrm{i}}=$ Disconfirmation with attribute $\mathrm{I} ; \mathrm{A}_{\mathrm{j}}=$ attitude toward attribute $\mathrm{I}$; $\mathrm{P}_{\mathrm{i}}=$ performance of attribute $\mathrm{I} ; \mathrm{n}=$ number of attributes.

The satisfaction function using disconfirmation or gap as variable is formulated as 
$\mathrm{S}_{\text {edu }}=\mathrm{f}\left(\mathrm{D}_{\mathrm{i}}\right)$

Multi-attributes weighted attributes model. Although there are a variety of alternative specifications of the multi-attribute model, the most prominent one is the Fishbein model (Bettman, Capon and Lutz, 1975), which may be formulated as

$\mathrm{A}_{\mathrm{I}}=\sum_{\mathrm{I}=1}^{n} \mathrm{I}_{\mathrm{i}} \mathrm{P}_{\mathrm{i}}$

where :

$\mathrm{A}_{\mathrm{I}}=$ attitude toward attribute $\mathrm{I} ; \quad \mathrm{P}_{\mathrm{i}}=$ performance of attribute $\mathrm{I}$;

$\mathrm{I}_{\mathrm{i}}=$ important weight given attribute $\mathrm{I} ; \quad \mathrm{n}=$ number of attributes.

\section{Data Analysis and Findings}

Service Attribute. In Table I, reliability analysis was performed on the five subscales by using Cronbach alpha. The high alpha coefficients demonstrate good internal consistency for the various measurement scales used. Table I also contains the product moment correlations among five service attributes and overall satisfaction. Overall satisfaction has a significant, positive correlation with each of the five satisfaction dimensions $(p<0.001)$. In particular, education quality, compensation and recognition have relatively higher correlation with overall satisfaction. Hence, Hypothesis 1a is supported.

Table I: Correlation matrix and Alpha Reliability Estimates for Factors

\begin{tabular}{|l|l|c|c|c|c|c|c|c|c|}
\hline & & \multicolumn{5}{|c|}{ Correlation Matrix } & Number of & Cronbach's \\
\hline & \multicolumn{1}{|c|}{ Factors } & $\mathbf{1}$ & $\mathbf{2}$ & $\mathbf{3}$ & $\mathbf{4}$ & $\mathbf{5}$ & $\mathbf{6}$ & Items & Alpha \\
\hline 1 & Education Quality & 1.00 & & & & & & 9 & 0.817 \\
\hline 2 & Studying Facilitation & 0.46 & 1.00 & & & & & 9 & 0.700 \\
\hline 3 & Social Life & 0.24 & 0.54 & 1.00 & & & & 9 & 0.835 \\
\hline 4 & Recognition & 0.73 & 0.39 & 0.15 & 1.00 & & & 9 & 0.856 \\
\hline 5 & Compensation & 0.72 & 0.43 & 0.22 & 0.71 & 1.00 & & 9 & 0.864 \\
\hline 6 & Overall Satisfaction & 0.56 & 0.33 & 0.31 & 0.41 & 0.48 & 1.00 & 9 & $/$ \\
\hline
\end{tabular}

Satisfied and dissatisfied. Two groups, satisfied and dissatisfied were formed based on the rated scale of "overall satisfaction". For more clarity, we leave respondents with the media score " 4 " out of consideration. Thus, all respondents with a scale ranging from " 1 " to " 3 " are classified as "dissatisfied", all respondents with scores ranging from " 5 " to " 7 " are classified as "satisfied". Table II shows the means of five primary attributes of higher education and overall satisfaction for satisfied and dissatisfied students. All of these dimensional means of satisfied students are significantly different from dissatisfied students at the level of $p<0.001$. Specifically, satisfied students gave higher scores for each service attribute than those of dissatisfied students. The order is somewhat different, for example, education quality received the highest mean performance among satisfiers, but received the second lowest mean for the dissatisfied group. The basic idea here is that these five service attributes are significantly related to both satisfied 
and dissatisfied students. Moreover, dissatisfied customers are always reluctant to report, and the number of this group of respondents is quite a bit lower. In this study, only 156 students are classified as dissatisfied among 1475 students. Therefore, we should analyze both satisfied and dissatisfied, instead of the dissatisfied group alone. Overall, Hypothesis $1 \mathrm{~b}$ is supported by the results.

Table II: Different Perceptions of Service Attributes Performance and Satisfaction Measures among Satisfied and Dissatisfied Students

\begin{tabular}{|l|c|c|c|c|c|c||c|c|}
\hline & \multicolumn{2}{|l|}{ Satisfied } & \multicolumn{2}{l|}{ Students } & \multicolumn{2}{l|}{ Dissatisfied Students } & & \\
\hline \multicolumn{1}{|c|}{ Dimensions } & Mean & & S. D & Mean & S. D & T-Value & Sig. \\
\hline Overall & 5.58 & 0.66 & 2.55 & 0.71 & 50.60 & 0.00 \\
\hline Compensation & 4.84 & 0.77 & 3.82 & 0.91 & 15.22 & 0.00 \\
\hline Social Life & 4.56 & 0.83 & 3.86 & 0.93 & 9.57 & 0.00 \\
\hline Facilities & 4.26 & 0.75 & 3.52 & 0.86 & 10.49 & 0.00 \\
\hline Recognition & 4.67 & 0.93 & 3.65 & 0.91 & 12.56 & 0.00 \\
\hline $\begin{array}{l}\text { Education } \\
\text { Quality }\end{array}$ & 4.91 & 0.77 & 3.56 & & 0.87 & 19.21 & 0.00 \\
\hline
\end{tabular}

Fit of Model Table III demonstrates the good fit of three models which are used to predict overall student satisfaction by employing the same database. The results suggest all three measures can significantly predict overall student satisfaction. Consistent with the statement of Jayanti and Jackson (1991), the R squares in Table III indicate that performance (0.447) can explain overall satisfaction better than both the multi-attributes and disconfirmation models. 
Table III: Stepwise Regression Results

\begin{tabular}{|l|l|l|l|l|}
\hline Models & Independent Variables & Beta & SIG. & $\mathbf{R}^{2}$ \\
\hline Performance Model & & & & $0.447(\mathrm{p}<0.001)$ \\
\hline & Education quality & 0.484 & 0.000 & \\
\hline & Social life & 0.192 & 0.000 & \\
\hline & Compensation & 0.146 & 0.000 & \\
\hline & Studying condition & 0.019 & 0.452 & \\
\hline Fishbein Multi- & Recognition & 0.000 & 0.975 & \\
\hline & & & & \multirow{2}{*}{ Attribute } \\
& & & & $0.368(\mathrm{p}<0.001)$ \\
\hline & Education quality & 0.436 & 0.000 & \\
\hline & Social life & 0.187 & 0.000 & \\
\hline & Compensation & 0.127 & 0.000 & \\
\hline & Recognition & -0.067 & 0.047 & \\
\hline Disconfirmations & Studying condition & -0.030 & 0.289 & \\
\hline & & & & $0.252(\mathrm{p}<0.001)$ \\
\hline & Education quality & 0.442 & 0.000 & \\
\hline & Compensation & 0.098 & 0.000 & \\
\hline & Recognition & 0.055 & 0.078 & \\
\hline & Social life & 0.046 & 0.063 & \\
\hline & Studying condition & 0.006 & 0.836 & \\
\hline
\end{tabular}

Hence, both our Hypotheses 3 and 4 are empirically confirmed. Additionally, perhaps the most interesting and surprising finding is that multi-attribute attitude has greater impact on satisfaction than the disconfirmation model has, although the disconfirmation model is the most popular one in the satisfaction research area.

Table III also sheds light on the relative importance of service attributes in effecting student satisfaction with higher education. All three methods indicate that the quality of education is the best predictor of student satisfaction, which is consistent with other findings (Hampton, 1993, Cook and Zallocco, 1979). As we previously mentioned, there is some diversity in the order and significance of four other attributes when using different models. For instance, social life significantly contributes to satisfaction in both the performance and multi-attributes models, whereas it is not significant in the disconfirmation model. Recognition is perceived to significantly explain the satisfaction only in the multi-attributes model. Also, compensation other than social life is in second position in the disconfirmation methods. This also explains why some conclusions conflict, even with the same database or similar research design while using different models. The rationale behind these differences needs be further studied and may yield some valuable findings. The relatively low $\mathrm{R}$ squares also indicate the difficulty of predicting student satisfaction, even with use of the best model and larger samples, due to its complexity and the diversity of student priorities and desires. 


\section{Student variables and service attributes.}

For analytical convenience, and due to space limitation, some student aspects are omitted. Eight characteristics are chosen for further consideration: age, gender, class, employment status, GPA, part-time work or full-time work; living on campus or not, part-time and full-time student. The findings in Table IV indicate that student characteristics have quite different effects on the performances and expectations of five education service attributes. Further discussion elucidates important points.

\section{Studying facilities.}

The result of a wide variety of students basically having no differences on the performance study, except for student with different GPA, is not surprising. However, as to expectation, students with different aspects obviously have various expectations for study facilities. Students who are younger, or in lower level classes, or non-working, or who have lower GPAs, or are part-time have higher expectations for study facilities than do others.

\section{Education quality.}

The performance of education quality received more attention by older, female students, or by students who were in a high level class, non-working, had higher GPAs, or lived on campus. The same thing happened for the expectation of education quality, except that there is correlation between part-time and full time students' expectation with quality. There is no significant difference between performance and expectation of education quality for specific students.

\section{Recognition.}

Students who are older, or female, or in a high level class, or working, or live off campus, or have high GPAs have a preference for being recognized by professors or education server providers. With regard to recognition, students with different ages, whether they are part-time or full time, have the same expectation in terms of recognition attributes. 


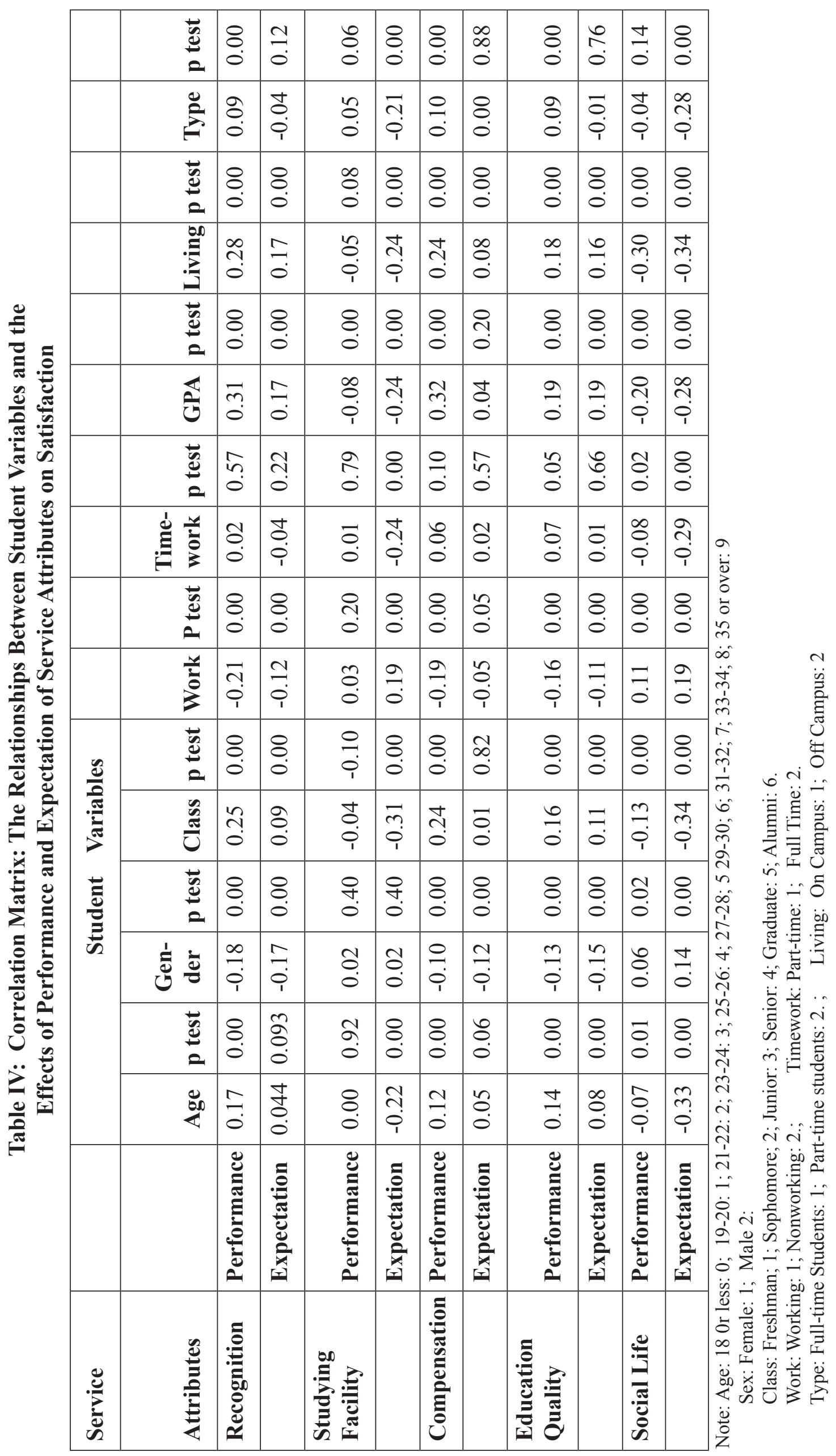




\section{Compensation.}

Students who are older, female, in a high level, have a high GPA care more for compensation, i.e, the ratio of output and input. For expectation of compensation, there is no significant correlation between older and younger students, or between higher level and lower level class students, or between part-time and full-time students.

\section{Social life.}

Finally, social life is more attractive to students who are young, male, in a lower level class, non-working, working part-time, have a relatively low GPA, and who live on campus. The only difference between performance and expectation is that full-time students have higher expectation for social life than those of part-time students while their perceived performance denotes no significant difference.

These findings are interesting to those administrators who are particularly attentive to individual or specific groups and who know how to accommodate the priorities and needs of different student groups, based on their demographic characteristics.

\section{Discussion}

The results of this research have implications for researchers as well as education administrators. The marketing mix-based service attributes are significantly related to overall satisfaction. Our results suggest that, instead of paying attention to dissatisfied students alone, it may be more appropriate to derive deep insights into what leads to satisfaction in the context of a service area such as higher education, This is due to (1) satisfied students are in the majority; and (2) dissatisfied students share basically the same perspective of service attributes. In assessing student satisfaction with higher education, performance of service attributes is demonstrated as the best indictor of satisfaction. In addition, the multi-attribute model performs better in explaining satisfaction than the disconfirmation model or gap analysis. Using different models can yield certain differences, even utilizing the same database.

The paper also shows that individual student characteristics indirectly impact satisfaction by influencing the performance and expectation of service attributes. Incorporation of individual characteristics within a suitable theoretical structure, as moderating variables, would prove to be a more promising direction for future research pursuits. Administrators should devote more attention to the different priorities and desires of the particular groups based on their demographic aspects. From a practitioner's standpoint, administrators need to adopt strategies to manage or positively influence the way in which students affect one another and to implement effective mechanisms by which they can support each other's experience. These interactions tend to improve student satisfaction with the education experience.

The instinctive reaction of education service providers is to assume that customer-to-customer interactions are beyond their control. Nevertheless, particularly in educational environments where the customer spends a longer period of time in the environment, the significance of customer-to-customer interaction may be greater than that of the customer-to-service-agent interaction. Rowley (1996) explores some of the approaches to customer compatibility management in higher education. Fundamentally, any assessment of satisfaction needs to acknowledge the mutual influence among customers. 


\section{References}

Astin, A. (1988), "Retaining and Satisfying Students", Education Record, vol.68, no.1, pp. 36-42.

Barry, T. E., GIlly, M.C., and Schucany, W. R.(1982), "Students as Consumers: Predicting Satisfaction", An assessment of Marketing Thought \& Practice, 1982 Educators' Conference Proceedings, pp. 109-112.

Bean, J. P., and Nick, V. (1994), "Gender Differences in College Student Satisfaction: ASHE Annual Meeting Paper", The Annual Meeting of the Association for the Study of Higher Education, November 10-13.

Berry, L. L., and Kehoe, W. J. (1980), "Problems And Guidelines In University Marketing”, in Marketing in the 80's, 1980 Educators' Conference Proceedings.

Bettman, J. R., Capon, N., and Lutz, R. J. (1995), "Cognitive Algebra in Multi-Attributes Attitude Models", Journal of Marketing Research, vol.7, no. 2, pp.151-164.

Betz, E., Klingensmith, J., and Menne, J. (1970). „The Measurement and Analysis of College Student Satisfaction,“ Measure and Evaluation in Guidance, vol.3, Summer, pp.110-118.

Braskamp, L. A., Wise, S. L., and Hengstler, D. D. (1979), "Student Satisfaction as a Measure of Departmental Quality,” Journal of Educational Psychology, vol. 25, Winter, pp 494-498.

Bruker, R. A., and Tallians L. E. (1985), "The Institutional Self-Study: First Step in a Viable Marketing Program," College and University, Fall, pp. 32-42.

Conant, J. S., Brown, J. J. and Mokwa, M. P. (1984), "Student Are Important Consumers: Assessing Satisfaction in a Higher Education Context" Journal of Marketing Education, vol.5, no. 2, pp. 13-22.

Cook, R. W. and Zallocco R. (1979), "A Multi-Attribute Model for the Prediction”, Academy of Marketing Science Proceedings, Academy of Marketing Science.

DeVore, J. R. and Handal, P. J. (1981), “The College Student Satisfaction Questionnaire: Test-retest Reliability Study", Journal of College Student Personnel, July.

Douglas, J. McClelland, R., Davies, J. (2008) "The Development of a Conceptual Model of Student Satisfaction with Their Experience in Higher Education", Quality Assurance in Education, vol. 16, iss: 1 , pp.19-35

Durvasula, S., Lysonski, S., and Madhavi, A.D. (2011),"Beyond Service Attributes: Do Personal Values Matter?", Journal of Services Marketing, vol. 25 no. 1, pp.33-46

Gruber, T., Fuß, S. Voss, R., and Gläser-Zikuda, M. (2010), "Examining Student Satisfaction with Higher Education Services: Using A New Measurement Tool", International Journal of Public Sector Management, vol. 23, no. 2, pp.105-123

Gwinner, K. P., and Beltramini, R. F. (1995), “Alumni Satisfaction and Behavioral Intentions: University versus Departmental Measures”, Journal of Marketing Education, Spring, pp. 34-40. 
Hampton, G.M. (1983), “College Student Satisfaction: Marketing's Approach For Evaluating Higher Education”, 1983 AMA Educators' Proceedings.

Hampton, G. M. (1993), "Gap analysis of College Student Satisfaction as a Measure of Professional Service Quality”, Journal of Professional Services Marketing, vol. 9, no. 1, pp. 115-128.

Hawes, J. M., and Glisan, G. (1993), “A Marketing Approach to Student Evaluation of A Department of Marketing”, 1983 AMA Educators' Proceedings.

Howard, G. S. and Maxwell S. E. (1980), "Correlation Between Student Satisfaction and Grades: a Case of Mistake Causation?", Journal of Educational Psychology, vol. 72, no. 6, pp. 810-20.

Iacobucci, D., Ostrom, A. and Grayson, K. (1995), "Distinguishing Service Quality and Customer Satisfaction: the Voice of the Consumer", Journal of Consumer Psychology, vol. 4, no. 3, pp. 277-303.

Johnston, R. (1995), "The Determinants of Service Quality: Satisfiers and Dissatisfiers", International Journal of Service Industry Management, vol. 6, no. 5, pp. 53-71.

Kelly, J. T. and Otto, A. M. (1986), "Campus leadership: Managing and Marketing through an Effective Institutional Research Program", New Directions for Community College, vol. 14, no. 4, pp. 75-83.

Krachenberg, A. R. (1984) "Bringing the Concept of Marketing to Higher Education", Journal of Higher Education, vol. 43, June, pp. 369-380.

Krishnan, S. and Gronhaug K. (1979), "A Multi-Attribute Approach to Consumer Satisfaction with a Professional Program", in Day, R. L., Refining Concepts and Measures of Consumer Satisfaction and Complaining Behavior, Indiana University.

LaTour, S. A. and Peat, N. C. (1978), "Conceptual and methodological issues in consumer satisfaction Research", in William L., Advanced in Consumer Research, vol. VI, Miami beach: Association of consumer research, pp. 431-37.

Lewis, C. T., Leach, E. R. and Lutz, L. L. (1983), “A Marketing Model for Student Retention”, NASPA Journal, vol. 20, no. 3, pp. 15-24.

Murphy, P. E. and McGarrity R. A. (1978), "Marketing Universities: A Survey of Student Recruitment Activities", College and University, vol. 53, Spring, pp. 249-261.

Oliver, R. (1978), "Measurement and Evaluation of Satisfaction Process in Retail Settings", Journal of Retailing, vol. 57, Summer, pp. 25-48.

Parasuraman, A., Zeithaml V. A. and Berry L. L. (1985), "A Conceptual Model of

Service Quality and Its Implications for Future Research”, Journal of Marketing, vol. 49, Fall, pp. 4150.

Patterson, P. G., Johnson, L. W. and Spreng R. A. (1997), "Modeling the Determinants of Customer Satisfaction for Business-to-Business professional Service", Journal of Marketing, vol. 25, no. 1, pp. 4-17. 
Pennington, D. C. et al. (1989), "Change in College Satisfaction across an Academic Term”, Journal of College Development, vol. 2, no. 1, pp. 49-57.

Polcyn, L. J. (1986), “A two-Instrument Approach to Student Satisfaction Measurement”, Vol. 62, no.1, pp. 18-24.

Powers, S. and Rossman, M. H. (1985), "Student Satisfaction with Graduate Education:

Dimensionality and Assessment in a College Education", Psychology: a Quarterly Journal of Human Behavior, vol. 22, no. 2, pp. 46-9.

Schmidt, S. L., Debevec, K., and Comm, C. L. (1987), “Marketing Majors' Satisfaction With Their College experience: Implications for Strategic Planning in Marketing Departments", Journal of education, vol.19, no. 3, pp. 58-63.

Spreng. R. A., MacKenzie S. B. and Olshavsky R. W. (1996), “A Reexamination of the Determinants of Consumer Satisfaction”, Journal of Marketing, vol. 60, July, pp. 15-32.

Stage, F. K. (1987), "Student Typologies and the Study of College Outcomes", Journal of the freshman year experience, vol. II, no. 3, pp. 247-57.

Starr, A., Betz, E. L. and Menne, J. (1972), "Difference in College Student Satisfaction: Academic Dropouts, Nonacademic Dropout, and Nondropout", Journal of Counseling Psychology, vol. 10, no. 4, pp. 318-22.

Sturtz, S. A. (1971), “Age Difference in College Student Satisfaction”, The Journal of Student Personnel, May, pp. 220-2.

Terkla, D. G. and Pagano, M. F. (1990), "The Impact of Financial Aid on Student Satisfaction. Air Annual Forum Paper", Paper Presented at the Annual Forum of the Association Institutional Research, 20.

Voss, G. B., Parasuraman A. and Grewal D. (1998), "The Roles of Price, Performance, and Expectations in Determining Satisfaction in Service Exchanges", Journal of Marketing, vol. 62, October, pp. 46-61.

Yang, Z. and Peterson R. (2004) "Customer Satisfaction, Perceived Value, and Loyalty: The Role of Switching Costs," Psychology \& Marketing, vol. 21, no. 10, pp. 799-822.

Yang, Z. and Fang X. (2004), "Online Service Quality Dimensions and Their Relationships with Satisfaction: A Content Analysis of Customer Reviews of Securities Brokerage Services," International Journal of Service Industry Management, vol. 15, no. 3, pp. 302-326.

Yang, Z., Peterson R., and Cai, S. (2003), "Services Quality Dimensions of Internet Retailing: An Exploratory Analysis," Journal of Services Marketing, vol. 17, no. 7, pp. 685-98.

Yang, Z., Peterson R., and Huang, L. (2001), "Taking the Pulse of Internet Pharmacies:

Online Consumers Speak Out on Pharmacy Services," Marketing Health Services, vol. 21, Summer, pp. 4-10. 
ABRC

Asia Business Research Corporation Limited 
MAG Scholar ${ }^{\circledR}$ Marketing in Asia Group

www.magscholar.com 